\title{
Determining the processing modes of the low carbon steel by high-precision plasma cutting based on dimensionless complexes
}

\author{
Aleksandr Loktionov ${ }^{1, *}$, Nadezhda Gaar $^{1}$ and Andrey Rakhimyanov ${ }^{1}$ \\ ${ }^{1}$ Novosibirsk State Technical University, Faculty of Mechanical Engineering and Technologies, \\ 630073 Prospekt K. Marks 20, Novosibirsk, Russia
}

\begin{abstract}
The results of the investigations on determining the processing modes during high-precision plasma cutting of low carbon steel based on the values of Peclet number and dimensionless power which provide the minimal value of deviation of the cut sides from perpendicularity are presented in the paper. The conditions of obtaining the cut of high quality from the viewpoint of minimizing the cut side deviation from perpendicularity are determined by cutting low carbon steel. The dependences of the cutting speed and the cut width on the processed material thickness, intended to determine the processing modes and adjustment of the linear dimensions are established. The investigations were made on the device of the thermal cutting "Termit PPl" based on the installation of the high-precision plasma cutting HiFocus 130i of Kjellberg firm by using the HiFocus ${ }^{\text {plus }}$ technology. Low carbon construction steel St3 was chosen as an investigated material. The thickness of the sheet material constituted $4 \mathrm{~mm}, 6 \mathrm{~mm}, 10 \mathrm{~mm}, 16 \mathrm{~mm}$ and $20 \mathrm{~mm}$.
\end{abstract}

\section{Introduction}

High-precision plasma cutting is one of the methods of the thermal cutting in the blank production [1-6]. It is used for obtaining blank parts from the sheet material, intended to be assembled in a mechanism. For this reason, the accuracy level of the cut sides after processing is one of the factors, which determines the necessity of additional mechanical processing because it is the main construction bases on which the position of a detail is in a mechanism.

The use of high-precision plasma cutting at the modes recommended by the equipment producer allows obtaining non-perpendicularity of the cut sides in the range of $+2^{\circ}$ till $-1^{\circ}$. This accuracy is not sufficient to exclude the further mechanical processing of a detail for assembling, including the welding. Thus, it is necessary to increase the accuracy of the angle dimensions after high-precision plasma cutting. However, the theoretical methods of describing the forming of the cut surface taking into consideration all the factors for highprecision plasma cutting are not well developed and cannot be a reliable basis for the

\footnotetext{
*Corresponding author: loktionov@corp.nstu.ru
} 
practical optimization. For this reason, in practice the choice of the cutting parameters is done empirically.

There are attempts of the mathematical modelling of the process [7 - 10], which are based on the description of the physical processes in the material during the high-speed heating. They give quite an objective picture of heat fields in the processing zone, but it does not allow determining the quantitative dependence of the characteristics of the cut accuracy on the processing modes. Nowadays there are no reliable methods of forecasting the cutting accuracy and the choice of the optimal mode parameters (power and the cutting speed) at a different thickness of the processed material. First of all, it is connected with a diversity and a complicated interaction of the physical processes during high-precision plasma cutting. The main of them are the distribution and absorption of plasma emission in the cut channel, heat distribution in the material and the formation of melting fusion, gas flow in the cut channel, emission of energy as a result of the exothermal reaction and the formation of metal oxides in using oxygen as a cutting and /or whirling gas, motion of the melting film under the influence of the gas flow. These processes, in their turn, depend on the processed material (thermo-physical properties and its thickness), technological modes (the current, the cutting speed, the gas composition, their pressure and rate). The combination of these factors determine the accuracy and quality of the cut during highprecision plasma cutting.

To solve these tasks with a great number of variables, the analysis of the physical systems by a similarity method is widely used.

\section{Experimental data}

The analysis of the physical systems by the similarity method suggests representing a large volume of data as dependences between generalized dimensionless parameters (complexes). It allows decreasing the number of independent variables and understand the physical essence of the processes taking place in the system investigated.

The described approach to investigating the physical processes of forming the cut of high quality was used by the authors of Papers [11,12] in studying the mechanisms of the cut forming during the laser cutting of materials. Establishing the optimal values of dimensionless parameters, the authors suggest correlations for determining the emission power and the cutting speed in which the cut surface has minimum roughness [13].

The validity of using such an approach to high-precision plasma cutting is explained by the fact that these processes are similar and based on the same mechanisms of the energy heat transfer from the source to the processed material. Besides, additional compression of the plasma arch used in technologies of high-precision plasma cutting provides the processing of the material as in the case of laser cutting under highly concentrated heat effect. According to Kirpichev-Gukhman theorem, it is possible to use the same criteria of similarity for both processes.

Generally, the perpendicularity $(\alpha)$ of the cut sides can be presented by the dependence on the following parameters:

$$
\alpha=\Phi\left(\mathrm{W}_{\text {total }}, \mathrm{V}, \mathrm{S}, \mathrm{t}, \mathrm{C}_{\mathrm{m}}, \lambda_{\mathrm{m}}, \rho_{\mathrm{m}}, \mathrm{T}_{\mathrm{m}}, \mathrm{L}_{\mathrm{m}}\right),
$$

where $\mathrm{W}_{\text {total }}$ - the power of the plasma column $[\mathrm{kW}] ; \mathrm{V}$ - the cutting speed $[\mathrm{m} / \mathrm{min}] ; \mathrm{S}$ the material thickness $[\mathrm{mm}] ; \mathrm{t}$ - the cut width $[\mathrm{mm}] ; \mathrm{C}_{\mathrm{m}}-$ specific heat $[\mathrm{kJ} /(\mathrm{kg} \cdot \mathrm{K})] ; \lambda_{\mathrm{m}}-$ the heat conductivity $[\mathrm{W} /(\mathrm{m} \cdot \mathrm{K})] ; \rho_{\mathrm{m}}$ - the density $\left[\mathrm{kg} / \mathrm{m}^{3}\right] ; \mathrm{T}_{\mathrm{m}}$ - the material temperature $[\mathrm{K}] ; \mathrm{L}_{\mathrm{m}}$ - the melting heat of the cut material $[\mathrm{kJ} / \mathrm{kg}]$.

Considering the processes of forming during high-precision plasma cutting which are characterized by a large number of variable factors as during laser processing, 
dimensionless generalized variables were used - dimensionless power (Q) and Peclet number $(\mathrm{Pe})[12,13]$. Peclet number is used for describing the processes of material heat by a moving heat source. The analysis of generalized parameters testifies that it is necessary to perform certain energy conditions to obtain the cut of high quality.

Taking into account the above said, the function (1) which determines the perpendicularity of the cut sides can be presented as follows:

$$
\alpha=\Phi(\mathrm{Pe}, \mathrm{Q})
$$

where $\mathrm{Q}$ - the dimensionless power (the ratio between the total power and energy losses in a unit of time due to the heat conductivity; $\mathrm{Q}=\left(\mathrm{W}_{\text {total }} \cdot 10^{6}\right) /\left(\lambda_{\mathrm{m}} \cdot \mathrm{S} \cdot \mathrm{T}_{\mathrm{m}}\right)$, where $\mathrm{W}_{\text {total }}$ - the total power of the plasma column $[\mathrm{kW}] ; \mathrm{S}-$ the material thickness $[\mathrm{mm}] ; \lambda_{\mathrm{m}}$ - the heat conductivity $[\mathrm{W} /(\mathrm{m} \cdot \mathrm{K})]$ and the melting temperature of the cut material $[\mathrm{K}]$, respectively;

$\mathrm{Pe}-$ Peclet number (the ratio between the cutting speed and the speed of spreading the heat wave from a cylindrical heat source with a diameter equal to the width of the cut channel $(\mathrm{t}) . \mathrm{Pe}=\mathrm{V} \cdot \mathrm{t} /\left(\gamma_{\mathrm{m}} \cdot 60 \cdot 1000\right)$, where $\mathrm{t}-$ the cut width $[\mathrm{mm}] ; \mathrm{V}$ - the cutting speed $[\mathrm{m} / \mathrm{min}] ; \gamma_{\mathrm{m}}-$ the temperature conductivity of the cut material $\left[\mathrm{m}^{2} / \mathrm{sec}\right]$.

It should be noted that the total power of the plasma column $\left(\mathrm{W}_{\text {total }}\right)$ during highprecision plasma cutting can be expressed in the following way:

$$
\mathrm{W}_{\text {total }}=\mathrm{W}_{\text {arc }}+\mathrm{W}_{\mathrm{ox}}=\mathrm{W}_{\mathrm{m}}+\mathrm{W}_{\text {cond }}+\mathrm{W}_{\text {plasm }}+\mathrm{W}_{\mathrm{atm}},
$$

where $\mathrm{W}_{\text {arc }}=\left(\mathrm{I}_{\mathrm{arc}} \cdot \mathrm{U}_{\mathrm{arc}}\right) / 1000$ - the power of the plasma arch $[\mathrm{kW}] ; \mathrm{I}_{\text {arc }}$ - the value of the arch current $[\mathrm{A}] ; \mathrm{U}_{\mathrm{arc}}-$ the voltage reduction $[\mathrm{V}]$.

As the investigated material is carbon steel, oxygen is used as a cutting gas. During the processing $\mathrm{FeO}$ oxides are formed in the cut channel according to the reaction:

$$
\mathrm{Fe}+1 / 2 \mathrm{O}_{2}=\mathrm{FeO}+\Delta \mathrm{H}
$$

In this case $\mathrm{W}_{\mathrm{ox}}=\left(\mathrm{k}_{\mathrm{ox}} \cdot \mathrm{V} \cdot \mathrm{t} \cdot \mathrm{S} \cdot \rho \cdot \Delta \mathrm{H} / \mathrm{M}_{\mathrm{Fe}}\right) /(60 \cdot 1000)$ - the power emitted during the oxidation reaction; $\mathrm{k}_{\mathrm{ox}}$ - the coefficient showing the relative number of iron atoms removed from the cut channel as $\mathrm{FeO} ; \mathrm{V}$ - the cutting speed $[\mathrm{m} / \mathrm{min}] ; \mathrm{t}$ - the cut width $[\mathrm{mm}] ; \mathrm{S}-$ the cut material thickness $[\mathrm{mm}] ; \rho$ - the density of the cut material $\left[\mathrm{kg} / \mathrm{m}^{3}\right] ; \Delta \mathrm{H}$ - the reaction energy $[\mathrm{kJ} / \mathrm{mol}] ; \mathrm{M}_{\mathrm{Fe}}-$ iron molar mass $[\mathrm{g} / \mathrm{mol}]$.

In calculating power $\left(\mathrm{W}_{\mathrm{ox}}\right)$ emitted during the oxidation reaction, the value $\mathrm{k}_{\mathrm{ox}}$ is taken as equal to 0.35 . The reaction energy $(\Delta \mathrm{H})$ constitutes $268.8 \mathrm{~kJ} / \mathrm{mol}$ and iron molar mass $\left(\mathrm{M}_{\mathrm{Fe}}\right)-55.8 \mathrm{~g} / \mathrm{mol}$.

$\mathrm{W}_{\mathrm{m}}=\left(\mathrm{V} \cdot \mathrm{t} \cdot \mathrm{S} \cdot \rho \cdot\left[\mathrm{C}_{\mathrm{m}} \cdot \Delta \mathrm{T}+\mathrm{L}_{\mathrm{f}}\right]\right) /\left(60 \cdot 10^{6}\right)$ - the power spent on heating and melting the material removed from the cut channel; $\mathrm{V}$ - the cutting speed $[\mathrm{m} / \mathrm{min}] ; \mathrm{t}$ - the cut width $[\mathrm{mm}] ; \mathrm{S}-$ the thickness of the cut material $[\mathrm{mm}] ; \rho$ - the density of the cut material $\left[\mathrm{kg} / \mathrm{m}^{3}\right] ; \mathrm{C}_{\mathrm{m}}$ - the heat capacity $[\mathrm{kJ} /(\mathrm{kg} \cdot \mathrm{K})] ; \mathrm{L}_{\mathrm{f}}$ - the melting heat $[\mathrm{kJ} / \mathrm{kg}] ; \Delta \mathrm{T}$ - the change in the material temperature $[\mathrm{K}]$.

In calculating power $\left(\mathrm{W}_{\mathrm{m}}\right)$ spent on heating and melting the material removed from the cut channel, the values of average specific heat capacity $\left(\mathrm{C}_{\mathrm{m}}=0.45 \mathrm{~kJ} /(\mathrm{kg} \cdot \mathrm{K})\right)$; the melting heat $\left(\mathrm{L}_{\mathrm{f}}=82 \mathrm{~kJ} / \mathrm{kg}\right)$ and changes in the material temperature $(\Delta \mathrm{T}=1,600 \mathrm{~K})$ are used.

$\mathrm{W}_{\text {cond }}$ - the power lost because of heat transfer from the cut zone due to heat conductivity;

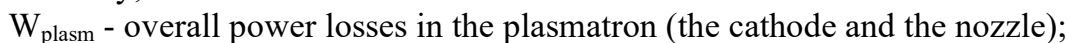

$\mathrm{W}_{\mathrm{atm}}$ - power losses in the atmosphere

The values of power $\mathrm{W}_{\text {cond }}, \mathrm{W}_{\text {plasm }}$ and $\mathrm{W}_{\text {atm }}$ for plasma cutting carbon steels can be equal to $60 \%, 8 \%$ and $32 \%$ of $\mathrm{W}_{\text {total }}$, respectively.

The investigations were conducted on the device of thermal cutting "Termit PPl" based on the installation of high-precision plasma cutting HiFocus $130 \mathrm{i}$ with using the HiFocus ${ }^{\text {plus }}$ 
technology. Low carbon construction steel St3 was chosen as the material investigated. Cutting the blank parts was done of the material with a thickness of $4 \mathrm{~mm}, 6 \mathrm{~mm}, 10 \mathrm{~mm}$, $16 \mathrm{~mm}$ and $20 \mathrm{~mm}$. Not less than five experiments were made for every cut thickness. The methods of assessing the non-perpendicularity of the cut sides correspond to the methods ISO 9013:2017 (Thermal cutting - classification of thermal cuts - geometrical product specification and quality tolerances).

The cutting current, the cutting velocity, pressure and gas rate are considered as technological parameters during high-precision cutting for any scheme of material cutting plasma. The current is determined by the size type of the nozzle used. The limit value of pressure and gas rate is determined by the chosen size type of a set of the plasmotron changeable parts. So, in determining technological parameters which influence the forming of the cut sides, it is possible to consider only the cutting speed as a controlling parameter $[14,15]$. At the preliminary stage before the description of the process, a number of experiments were conducted for determining the optimal value of the cutting speed at which the value of deviation from the cut perpendicularity is close to zero. The dimensionless power $(\mathrm{Q})$ and Peclet number $(\mathrm{Pe})$ were also determined according to the formulas $(2-3)$. The results are presented in Table 1 .

Table 1.

\begin{tabular}{|c|c|c|c|c|c|c|c|c|c|c|c|c|}
\hline 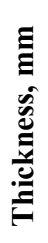 & 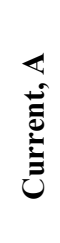 & 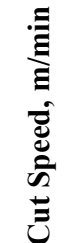 & 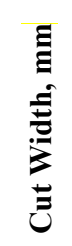 & 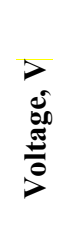 & 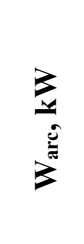 & 药 & 吾 & 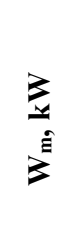 & 0 & $\stackrel{0}{2}$ & 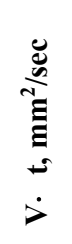 & 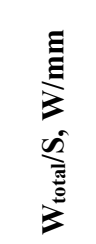 \\
\hline 4 & 50 & 1.45 & 1.65 & 119 & 5.95 & 2.09 & 8.04 & 0,96 & 16.34 & 1.75 & 39.8 & 2010.4 \\
\hline 6 & 50 & 1.16 & 1.7 & 127 & 6.35 & 2.59 & 8.94 & 1.19 & 12.10 & 1.44 & 32.8 & 1489.3 \\
\hline 10 & 130 & 0.96 & 2.68 & 135 & 17.55 & 5.62 & 23.17 & 2.59 & 18.83 & 1.88 & 42.8 & 2317.3 \\
\hline 15 & 130 & 0.9 & 2.5 & 144 & 18.72 & 7.38 & 26.10 & 3.40 & 14.14 & 1.65 & 37.5 & 1739.7 \\
\hline 20 & 130 & 0.9 & 2.4 & 150 & 19.50 & 9.44 & 28.94 & 4.35 & 11.76 & 1.58 & 36.0 & 1447.1 \\
\hline
\end{tabular}

\section{Results of the Research and Discussion}

The dependence of Peclet number on dimensionless power was done by using the data of Table 1 presented in Figure 1.

The dependence of Peclet number (Pe) on the dimensionless power (Q) can be represented as a linear dependence $(\mathrm{Pe}=0.0527 \mathrm{Q}+0.8839)$ obtained by the method of the least squares through the points, which correspond to optimal values of the cut speed with the approximation to $88 \%$. For the dependence mentioned, Peclet number is in the range of 1.4 to 1.9 . The relative constancy of Peclet number values at a different thickness of the processed material allows stating that there is a similarity of processes for all the investigated thicknesses during high-precision plasma cutting. However, from the technological viewpoint, the dependence of the optimal cutting speed on the dimensionless power in the coordinates $\mathrm{V} \cdot \mathrm{t}, \mathrm{W}_{\text {total }} / \mathrm{S}$ presented in Figure 2 is of the greatest interest. The diagram mentioned differs from diagram 1 in only dimensional constants, which characterize the material thermo-physical properties. The dependence obtained can also be described by the linear function (with the approximation validity to $89 \%$ ): 
$\mathrm{W}_{\text {total }} / \mathrm{S}=0.0098 \cdot \mathrm{V} \cdot \mathrm{t}+20.203$ characterized by the coefficient $\left.\mathrm{W}_{\text {total }} / \mathrm{V} \cdot \mathrm{S} \cdot \mathrm{t}\right)=102 \mathrm{~J} / \mathrm{mm}^{3}$. This coefficient characterizes the energy value put in a unit of the removed material volume.

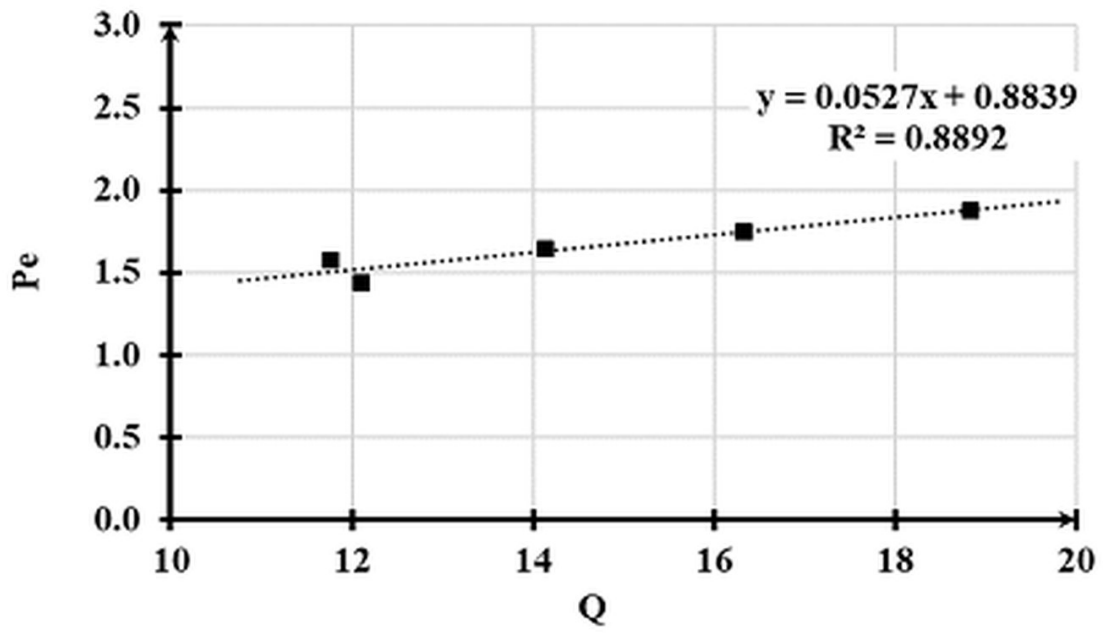

Fig. 1. The value of Peclet number (Pe) depending on the dimensionless power (Q)

The minor change in Peclet number in the investigated range of the material thickness allows using its average value equal to 1.66 for any cut thickness. In this case, the average value of dimensionless power is 14.6. Following this condition, the combination of the plasma column power and the cut material thickness as well as the cutting speed and the cut width for low carbon steel St3 are:

$$
\begin{gathered}
\mathrm{W}_{\text {total }} / \mathrm{S}=1800 \mathrm{~W} / \mathrm{mm} \\
\mathrm{V} \cdot \mathrm{t}=37.8 \mathrm{~mm}^{2} / \mathrm{sec}
\end{gathered}
$$

For the practical use of providing the high quality cutting, it is necessary to express them by designated parameters of the process. Such conditions for plasma cutting are the cutting current, the gas pressure and the cutting speed. The cut width is not considered as the designated value. It depends on the cutting speed and the cut material thickness. 


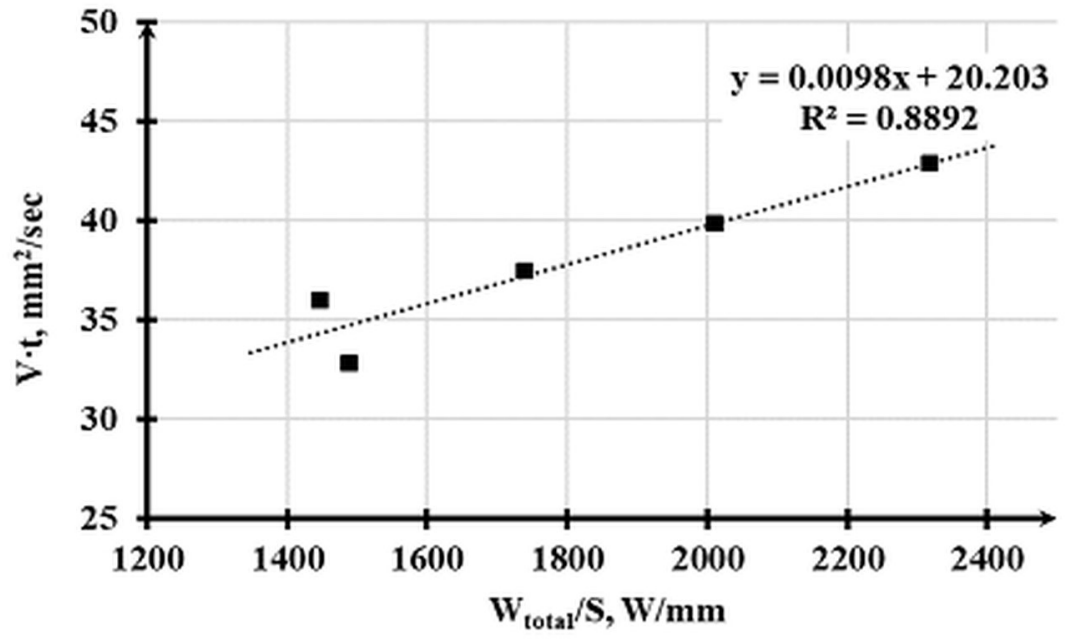

Fig. 2. Dependence of the optimal cutting speed on the power in the coordinates $V \cdot t, W_{\text {total }} / S$

It is necessary to express the value of the cut width by one of the parameters, the value of which is known before but not after the processing. This parameter can be the cut material thickness. It should be noted that energy parameters of the process during plasma cutting unlike laser cutting cannot be changed continuously. The cutting current is determined by a type size of the nozzle. So, determining the dependence of the cut width on the cut material thickness should be considered for every size type of the nozzle. The paper under consideration presents the investigations on determining the dependence of the cut width on the cut material thickness for HiFocus ${ }^{\text {plus }}$ technology for nozzle S2012x (the maximum cutting current $\mathrm{I}=130 \mathrm{~A}$ ), which is used for cutting low carbon steel in the thickness range of $10 \mathrm{~mm}$ to $25 \mathrm{~mm}$. The experimental results are presented in Figure 3.

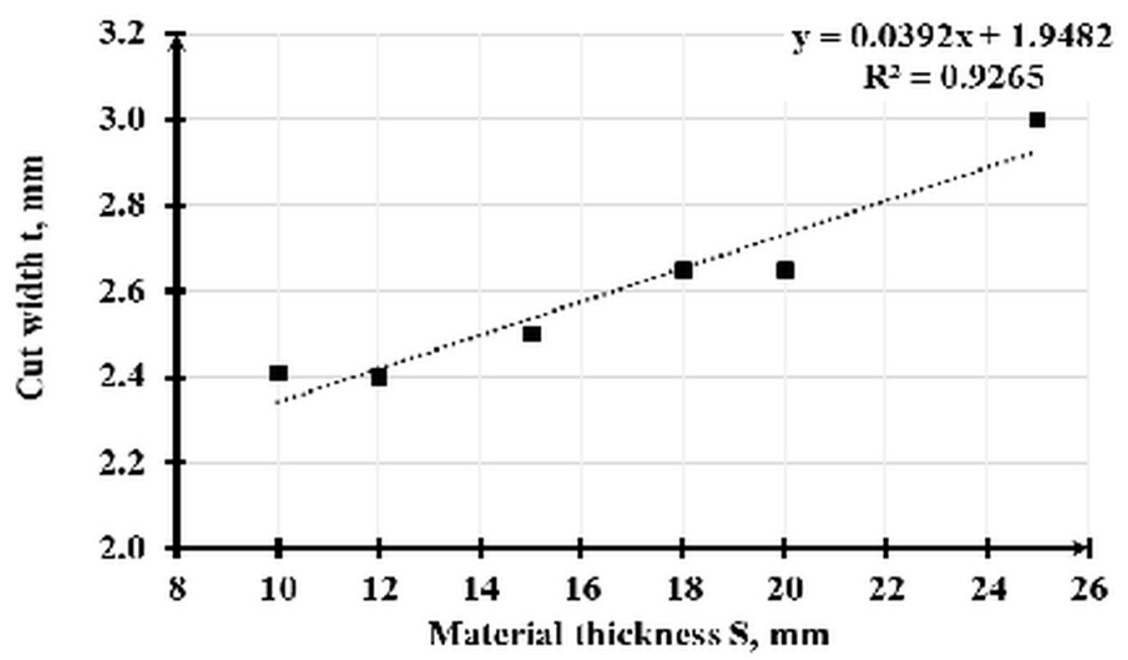

Fig. 3. Dependence of the cut width on the thickness of low carbon steel St3 in using nozzle S2012x for HiFocus ${ }^{\text {plus }}$ technology 
The obtained ratio of the cut width and the processed material thickness with the approximation accuracy $\mathrm{R}=0.92 \%$ are described by the linear dependence:

$$
\mathrm{t}=0.0392 \cdot \mathrm{S}+1.9482
$$

Taking into considerations the dependences (6) and (7) it is possible to obtain the dependence of the optimal speed of cutting $[\mathrm{m} / \mathrm{min}]$ on the thickness of the processed material for the investigated technology HiFocus ${ }^{\text {plus }}$ by using the nozzle S2012x:

$$
\mathrm{V}=(37,8 \cdot 60) /((0,0392 \cdot \mathrm{S}+1,9482) \cdot 1000)
$$

Dependences (8) and (7) during cutting the low carbon steel at different material thickness allow calculating the optimal value of the cutting speed and the expected value of the cut width.

\section{Conclusions}

The analysis of the results obtained in investigating high-precision plasma cutting by dimensionless parameters allows reaching the following conclusions:

1. Pe number in cutting sheet materials of low carbon steel in the thickness range of $4 \mathrm{~mm}$ to $25 \mathrm{~mm}$ is equal to $1.4-1.9$. For the practical use, it is possible to apply the average value of Pe number equal to 1.66 and the dimensionless power of 14.6.

2. The minimal cut deviation from the perpendicularity for HiFocus ${ }^{\text {plus }}$ technology is achieved by constant ratio of the plasma column power and a unit of volume of the material removed from the cut channel, which is equal to $102 \mathrm{~J} / \mathrm{mm}^{3}$ in the whole investigated thickness range of cutting low carbon steel ST3.

3. The dependences of the optimal cutting speed of low carbon steel and the expected cut width in the investigated range of the processed material thickness are established.

\section{References}

1. A.K. Rakhimyanov, N.P. Gaar, A.A. Loktionov, MATEC Web of Conferences, 224, 01011 (2018)

2. Ian Kirkpatrick, Aircraft Engineering and Aerospace Technology, 70:3, 215 (1998)

3. P. Patel, S. Soni, N. Kotkunde, N. Khanna, Materials Today: Proceedings, 5:2-1, 6023 (2018)

4. S. Bhowmick, J. Basu, G. Majumdar, A. Bandyopadhyay, Materials Today: Proceedings, 5:2-1, 4541 (2018)

5. E. Gariboldi, B. Previtali, Journal of Materials Processing Technology, 160:1, 77 (2005)

6. W. Xue, K. Kusumoto, K. Nezu, Science and Technology of Welding and Joining, 10:1, 44 (2005)

7. M. Senthil Kumar, B. Dhanasekar, G. Ranga Janardhana, K. S. Jayakumar, International Journal of Intelligent Information Processing, 3:2, 77 (2012)

8. Milan Kumar Das, Kaushik Kumar, Tapan Kr. Barman, Procedia Materials Science, 5, 1550 (2014)

9. K. Salonitis, S. Vatousianos, Procedia CIRP, 3, 287 (2012)

10. Cebeli Özek, Ulaş Çaydaş, Engin Ünal, Materials and Manufacturing Processes, 27:1, 95 (2012) 
11. A.M. Orishich, V.B. Shulyatyev, A.G. Malikov, VI Int. Symposium Laser Technologies and Lasers: Smolyan, Bulgaria, 15 (2009)

12. A.G. Malikov, A.M. Orishich, V.B. Shulyatyev, International Journal of Machine Tools \& Manufacture, 49, 1152 (2009)

13. V.M. Fomin, A.A. Golyshev, A.G. Malikov, A.M. Orishich, V.B. Shulyat'ev, Journal of Applied Mechanics and Technical Physics, 56:4, 726 (2015)

14. K.M. Rakhimyanov, A.A. Loktionov, A.K. Rakhimyanov, N.P. Gaar, Obrabotka metallov: metal working and material science, 20:2, 18 (2018)

15. A. Loktionov, N. Gaar, Applied Mechanics and Materials, 788, 46 (2015) 